\title{
Efeito da adição de agentes tróficos na dieta de leitões desmamados sobre a estrutura e ultraestrutura do intestino delgado e sobre o desempenho
}

[The effect of the addition of trofic agents in weaned piglet diets over the structure and ultra-structure of small intestine and over performance]

\author{
F.M. Tucci ${ }^{1}$, M.C. Thomaz ${ }^{2}$, L.S.O. Nakaghi ${ }^{2}$, M.I. Hannas ${ }^{3}$, A.J. Scandolera ${ }^{4}$, F.E.L. Budiño ${ }^{5 *}$ \\ ${ }^{1}$ Ministério da Agricultura, Pecuária e Abastecimento - Brasília, DF \\ ${ }^{2}$ Faculdade de Ciências Agrárias e Veterinárias - UNESP - Jaboticabal, SP \\ ${ }^{3}$ Alltech do Brasil - Curitiba, PR \\ ${ }^{4}$ Departamento de Ciências Agrárias - UFPR - Curitiba,PR \\ ${ }^{5}$ Instituto de Zootecnia/APTA/SAA - Nova Odessa, SP
}

\begin{abstract}
RESUMO
Foram estudados os efeitos da glutamina, dos ácidos graxos poli-insaturados e da parede celular de levedura (PCL) sobre a estrutura e ultraestrutura do intestino delgado e o desempenho de leitões. Foram utilizados 45 leitões, desmamados aos 21 dias de idade, para testar os seguintes tratamentos: T1 - dieta basal; T2 - dieta basal $+1 \%$ de glutamina; T3 - dieta basal $+0,2 \%$ de PCL; T4 - dieta basal $+5 \%$ de óleo de peixe. Nos dias sete e 14 pós-desmame, foram abatidos cinco leitões de cada tratamento. Os aditivos testados não alteraram a altura e a densidade dos vilos nem a profundidade das criptas do intestino delgado. Foi observado efeito de idade, mostrando redução na altura e na densidade dos vilos e na profundidade das criptas após o desmame. No duodeno e jejuno, foram observados maiores valores de relação vilo:cripta, que aumentaram com a idade pósdesmame. Ocorreram redução da altura dos microvilos do duodeno aos sete dias e aumento da largura dos microvilos do jejuno aos 14 dias pós-desmame. A área de superfície apical dos enterócitos não foi alterada pelos fatores estudados. Os aditivos estudados não foram eficientes em prevenir a atrofia da mucosa intestinal do jejuno, ao não interferir na sua ultraestrutura. Os aditivos incluídos na dieta não influenciaram o desempenho dos leitões no pós-desmame.
\end{abstract}

Palavras-chave: leitão, cripta, glutamina, microvilo, prebiótico, vilo

\begin{abstract}
The effects of glutamine, poliunsatured fatty acids and cellular wall of yeast (CWY) under the structure and ultra structure of the small gut and the performance of the piglets were studied. Forty five piglets weaned at 21 days were used to test the following treatments: T1 - basal diet; T2 - basal diet + $1 \%$ of glutamine; T3 - basal diet $+0,2 \%$ of CWY; T4 - basal diet $+5 \%$ of fish oil. At seven and 14 post weaning days, five piglets of each treatment were slaughtered. The height, density of villus and depth of small gut crypts were not altered by the inclusion of additives. The effect of age was observed, showing a reduction in the height and density of villus and depth of crypts after weaning. In duodenum and jejunum higher values were observed in the relation villus:crypt, which increased with the post wean age. There was a decrease in the height of microvillus of the duodenum at 7 days and an increase of the width of the microvillus of jejunum at 14 days after wean. The area of the apical surface of the enterocytes was not altered by the studied factors. The studied additives were not efficient to prevent the atrophy of the intestinal mucosa of the jejunum, since they did not interfere on its ultra structure. Piglet performance was not affected by the additives included in the diet.
\end{abstract}

Keywords: piglet, crypt, glutamine, microvillus, prebiotic, villus

Recebido em 30 de março de 2010

Aceito em 9 de junho de 2011

*Autor para correspondência (corresponding author)

E-mail: fbudino@iz.sp.gov.br

Projeto financiado pela FAPESP 


\section{INTRODUÇÃO}

Durante a fase pós-desmame, os leitões são submetidos a diversos fatores estressantes, que causam redução no crescimento. Verificam-se alterações histológicas e bioquímicas no intestino delgado, como atrofia dos vilos e hiperplasia das células das criptas, e, consequentemente, redução na capacidade de digerir alimentos e absorver nutrientes da dieta ( $\mathrm{Xu}$ et al., 2000). A capacidade absortiva do intestino é diretamente proporcional à superfície disponível para absorção, a qual depende do tamanho e do número de vilos, bem como de microvilos (Macari, 1998).

A atrofia dos vilos, normalmente observada no período pós-desmame, pode ser causada tanto pelo aumento na taxa de extrusão como pela diminuição na taxa de renovação. Se o encurtamento do vilo ocorrer via aumento na taxa de extrusão, então este estará associado a um aumento na proliferação celular da cripta e, geralmente, a um aumento de sua profundidade. A atrofia dos vilos também pode estar relacionada com a diminuição da divisão celular nas criptas (Pluske, 2001).

Há evidências de que a ingestão de alimento e sua presença física no trato gastrintestinal são necessárias para manter a estrutura e a função da mucosa intestinal (Pluske, 2001). Porém, no período imediato após o desmame, deve haver um certo grau de interação entre nível de nutriente e desenvolvimento intestinal, mas há principalmente um componente de resposta adaptativa, o qual independe da ingestão de nutrientes (Marion et al., 2005).

A glutamina é o aminoácido livre encontrado em maior concentração no leite da porca, aos 21 dias de lactação, e é considerada a principal fonte energética para os enterócitos dos leitões (Wu e Knabe, 1994). Durante o seu processo de hidrólise, são gerados produtos, tais como fumarato e aspartato, que podem entrar diretamente no ciclo de Krebs para gerar ATP, evidenciando, assim, o papel da glutamina como substrato energético para os enterócitos dos leitões (Stryer, 1992). Chow e Zhang (1998) observaram que a suplementação de glutamina diminuiu a morte celular e sugeriram que este mecanismo é tão importante quanto o do estímulo da proliferação celular, em condições de estresse, para manter a estrutura e a função intestinal. O uso de glutamina na dieta de leitões tem mostrado resultados positivos na manutenção da estrutura do intestino por ocasião do desmame (Wu et al., 2006), e melhor resposta imune frente à infecção por Escherichia coli (Yi et al., 2005).

A administração de ácidos graxos poliinsaturados para leitões que sofreram restrição alimentar melhorou a recuperação das lesões histopatológicas do intestino delgado (LópezPedrosa et al., 1999). Em uma revisão sobre os efeitos dos ácidos graxos poli-insaturados sobre o desenvolvimento de leitões, Leskanich e Noble (1999) relataram que estes ácidos graxos afetam o sistema imune dos animais melhorando sua resposta frente a desafios a doenças infecciosas. A inclusão de diferentes porcentagens $(0$ a $8 \%)$ e fontes de lipídeos (óleo de soja e óleo de coco) na dieta de leitões, na fase de creche, não alterou a altura dos vilos do duodeno e provocou redução na altura dos vilos do jejuno (Pimenta $e t$ al., 2002), não interferindo no desempenho dos leitões.

Outro aditivo que também pode afetar positivamente a mucosa intestinal, por meio da alteração da microbiota, é o mananoligossacarídeo (prebiótico), que age de duas maneiras: no fornecimento de nutrientes a bactérias desejáveis ou na eliminação de microrganismos patogênicos (Iji e Tivey, 1998). Uma das principais fontes de mananoligossacarídeos é a parede celular de levedura (Saccharomyces cerevisiae) (Spring, 2000). A adição de $0,2 \%$ de mananoligossacarídeo à dieta de leitões desmamados mostrou resultados positivos sobre a estrutura do intestino delgado, aumentando a altura dos vilos e a relação vilo/cripta (Santos et al., 2002a, b).

O objetivo deste trabalho foi o de avaliar se a inclusão de glutamina, ácidos graxos poliinsaturados ou parede celular de levedura na dieta de leitões desmamados pode alterar a estrutura e a ultraestrutura da mucosa intestinal e o desempenho de leitões desmamados.

\section{MATERIAL E MÉTODOS}

Foram utilizados 45 leitões, homogêneos quanto à linhagem, desmamados aos 21 dias de idade, 
com média de peso de $6,17 \pm 0,55 \mathrm{~kg}$. Os animais foram alojados na Câmara Climática do Departamento de Morfologia e Fisiologia Animal da FCAV/UNESP, Câmpus de Jaboticabal, e mantidos em temperatura termoneutra $\left(26,5 \pm 1,1^{\circ} \mathrm{C}\right)$, onde receberam ração e água à vontade e iguais condições de manejo.

Os tratamentos foram: 1 - dieta basal; 2 - dieta basal $+1 \%$ de glutamina; 3 - dieta basal $+0,2 \%$ de parede celular de levedura (prebiótico); e 4 dieta basal $+5 \%$ de óleo de peixe. A dieta basal (Tab. 1) foi formulada para atender ou exceder os níveis nutricionais propostos pelo NRC (Nutrients..., 1998). O óleo de peixe utilizado no tratamento 4 substituiu o óleo de soja usado na dieta basal dos demais tratamentos. A energia metabolizável do óleo de peixe é ligeiramente inferior à do óleo de soja, provocando uma diferença de $20 \mathrm{kcal}$ de energia por $\mathrm{kg}$ de ração, porém o nível de gordura das dietas foi mantido igual.

Os produtos avaliados foram: o aminoácido sintético L-glutamina $(99,0 \%)$; o prebiótico Pronady ${ }^{\circledR} 500$, formado por parede celular da levedura Sacharomyces cerevisae, e o óleo de peixe, fornecido pela Pesqueira Pacific Star, Chile. A dosagem utilizada foi definida conforme recomendação do fabricante ou dados da literatura.

No dia do desmame, foram abatidos cinco leitões (controle) e, nos dias sete e 14 pós-desmame, cinco leitões de cada tratamento. Antes de serem abatidos, os animais passaram por um período de jejum alimentar de 16 horas, sem restrição de água. Logo após o abate, foram colhidas amostras do duodeno, jejuno e íleo para microscopia de luz e eletrônica de varredura. Para microscopia eletrônica de transmissão, foram colhidas amostras do duodeno e do jejuno.

O processamento e a análise das amostras da microscopia de luz e eletrônica de varredura foram realizados, respectivamente, no Laboratório de Histologia do Departamento de Morfologia e Fisiologia Animal e no Laboratório de Microscopia Eletrônica da FCAV/UNESP, campus de Jaboticabal. O processamento e a análise das amostras da microscopia eletrônica de transmissão foram realizados no Centro de
Microscopia Eletrônica do Instituto de Biociências da UNESP, campus de Botucatu.

Tabela 1. Composição centesimal e nutricional da dieta basal

\begin{tabular}{|c|c|}
\hline Ingrediente & $\%$ \\
\hline Milho & 41,99 \\
\hline Farelo de soja & 19,00 \\
\hline Leite em pó desnatado & 26,00 \\
\hline Açúcar & 2,00 \\
\hline Sal & 0,50 \\
\hline Calcário calcítico & 0,66 \\
\hline Fosfato bicálcico & 1,44 \\
\hline Antioxidante & 0,01 \\
\hline L-lisina & 0,14 \\
\hline DL-metionina & 0,15 \\
\hline L-treonina & 0,11 \\
\hline Suplemento mineral ${ }^{1}$ & 0,20 \\
\hline Suplemento vitamínico ${ }^{2}$ & 0,30 \\
\hline Óleo de soja (ou peixe) & 5,00 \\
\hline Veículo $^{3}$ & 2,50 \\
\hline Total & 100,00 \\
\hline \multicolumn{2}{|l|}{ Nível nutricional (calculado) } \\
\hline Energia metabolizável (kcal/kg) & 3.500 \\
\hline Proteína bruta (\%) & 21,10 \\
\hline 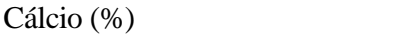 & 1,00 \\
\hline Fósforo disponível (\%) & 0,56 \\
\hline Lisina $(\%)$ & 1,50 \\
\hline Metionina $(\%)$ & 0,56 \\
\hline Metionina+cistina (\%) & 0,87 \\
\hline Treonina $(\%)$ & 0,98 \\
\hline Triptofano (\%) & 0,27 \\
\hline
\end{tabular}

1 - Suplemento mineral - níveis de garantia por kg de ração: Ferro $80 \mathrm{mg}$, Cobre $70 \mathrm{mg}$, Manganês $40 \mathrm{mg}$, Zinco $80 \mathrm{mg}$, Cobalto $0,72 \mathrm{mg}$, Iodo $1,68 \mathrm{mg}$, Selênio $0,24 \mathrm{mg}$.

2 - Suplemento vitamínico - níveis de garantia por kg de ração: Vit. A 12.000UI, Vit. D-3 3.000U.I, Vit. E 30mg, Vit. K-3 9mg, Vit. $B_{12} 27 \mathrm{mcg}$, Vit. $B_{2} 11,4 \mathrm{mg}$, Biotina $0,12 \mathrm{mg}$, Pantotenato de Cálcio $18 \mathrm{mg}$, Niacina $42 \mathrm{mg}$, Colina $300 \mathrm{~g}$.

3 - Os aditivos testados (glutamina e prebiótico) foram incluídos em substituição ao veículo (caulim), com exceção do óleo de peixe, que foi incluído em substituição ao óleo de soja.

As amostras colhidas foram fixadas em solução de Boiun por 24 horas, lavadas em água corrente e álcool etílico $70 \%$ para retirada do fixador e, posteriormente, foram desidratadas em séries crescentes de álcoois (70 a 100\%), diafanizadas em xilol e incluídas em parafina. A microtomia foi feita na espessura de $5 \mu \mathrm{m}$, realizando-se de 12 a 14 cortes semisseriados para cada segmento de cada animal, e a coloração dos cortes foi com ácido periódico de Shift (PAS). As análises morfométricas do epitélio intestinal foram feitas em um sistema analisador de imagens da kontron elektronik (Vídeo Plan), com aumento de 230 vezes. Os parâmetros estudados foram altura dos 
vilos, profundidade das criptas e relação vilo:cripta.

Foram colhidas amostras do duodeno, jejuno e íleo de aproximadamente $1 \mathrm{~cm}$, as quais foram lavadas em tampão fosfato $(0,1 \mathrm{M} \mathrm{e} \mathrm{pH} 7,4)$, fixadas em glutaraldeído 3\%, lavadas várias vezes no mesmo tampão, pós-fixadas em tetróxido de ósmio a $2 \%$ por duas horas e lavadas novamente em tampão fosfato. Em seguida, foram desidratadas em série de concentração crescente de álcool etílico, secas em secador de ponto crítico, usando $\mathrm{CO}_{2}$, montadas, metalizadas com ouro paládio, observadas e eletronmicrografadas em microscópio eletrônico de varredura Jeol, JSM-5410, operado em $15 \mathrm{kV}$. Foram feitas eletronmicrografias em cinco áreas de cada amostra para estimar a média da densidade dos vilos (número de vilos $\left./ 539.220 \mu \mathrm{m}^{2}\right)$.

As porções do intestino (duodeno e jejuno) foram lavadas em tampão fosfato $(0,1 \mathrm{M}$ e $\mathrm{pH}$ 7,4 ), fixadas em glutaraldeído $3,0 \%$ por 24 horas, lavadas no mesmo tampão, pós-fixadas em tetróxido de ósmio a $1 \%$ por 2 horas a $4^{\circ} \mathrm{C}$, lavadas em água destilada e desidratadas em série crescente de acetona (50, 70, 90 e 100\%). Após a desidratação, o material foi infiltrado com uma mistura 1:1 de acetona-resina Araldite durante 24 horas. Esta mistura foi desprezada, e o material foi incluído em resina Araldite e mantido em estufa a $60^{\circ} \mathrm{C}$ por 48 horas para polimerização. Foi feita a aparagem dos blocos para retirada do excesso de resina e preparo para os cortes. Por meio de cortes semifinos, de $0,5 \mu \mathrm{m}$ de espessura, corados com solução aquosa de azul de toluidina, foram escolhidos os campos para realização dos cortes ultrafinos. Estes cortes foram feitos em ultramicrótomo com navalha de diamante, montados em grades de cobre, contrastados com acetato de uranila e citrato de chumbo. Os microvilos foram eletronmicrografados em microscópio eletrônico de transmissão Jeol JSM-5410. Nas eletronmicrografias, com aumento de 17.000 vezes, foram analisados os parâmetros morfométricos em analisador de imagens da kontron elektronik (Vídeo Plan).

Foram analisados os seguintes parâmetros morfométricos: altura e largura dos microvilos $(\mu \mathrm{m})$; diâmetro apical dos enterócitos (distância entre dois complexos juncionais, em $\mu \mathrm{m}) \mathrm{e}$ densidade dos microvilos (número de microvilos $/ \mu \mathrm{m}^{2}$ ). A área de superfície apical dos enterócitos foi calculada segundo Ferrer et al. (1995), usando-se o diâmetro apical dos enterócitos e o fator de ampliação dos microvilos. O desempenho foi avaliado pelo ganho de peso, consumo de ração e conversão alimentar, mensurados semanalmente. $\mathrm{Na}$ primeira semana, foram utilizados os dados de 40 leitões e, na segunda semana, de 20 leitões.

Foi utilizado o delineamento em blocos ao acaso, em esquema fatorial $4 \times 2+1$ (quatro dietas $\mathrm{x}$ duas épocas de abate + um grupo-controle), com cinco repetições para a microscopia de luz, e três repetições para as microscopias eletrônicas, sendo a unidade experimental constituída por um animal. A análise de variância foi realizada por meio do procedimento GLM do SAS (1993), com as médias dos tratamentos comparadas pelo teste Tukey (5\%). O comportamento das variáveis-resposta em relação às idades de abate (dias pós-desmame) foi estimado pela análise de regressão linear, testando-se modelos polinomiais.

\section{RESULTADOS E DISCUSSÃO}

As probabilidades (teste F) obtidas pela análise de variância para os valores de altura dos vilos, profundidade das criptas e relação vilo/cripta do duodeno, jejuno e íleo estão apresentadas na Tab. 2.

A adição de glutamina, parede celular de levedura (prebiótico) ou ácidos graxos poliinsaturados na dieta dos leitões não alterou $(\mathrm{P}>0,05)$ a altura dos vilos e a profundidade das criptas, nem a relação vilo:cripta do intestino delgado dos leitões no período pós-desmame. Estes dados diferem dos apresentados por Abreu e Donzele (2008), que relataram efeito da adição de $1 \%$ de glutamina na dieta de leitões, prevenindo a atrofia dos vilos do jejuno medial no pós-desmame. López-Pedrosa et al. (1999) verificaram melhor recuperação de lesões histológicas no intestino delgado de leitões submetidos à restrição alimentar que receberam ácidos graxos poli-insaturados na dieta. Santos et al. (2002a) observaram que a adição de prebiótico à dieta de leitões, na fase de creche, aumentou a altura dos vilos. 
Tabela 2. Probabilidades (teste F) obtidas pela análise de variância para a altura dos vilos, profundidade das criptas e relação vilo:cripta do duodeno (D), jejuno (J) e íleo (I) dos leitões, em função do número de dias pós-desmame (DPD) e da dieta

\begin{tabular}{|c|c|c|c|c|c|c|c|c|c|}
\hline \multirow[b]{2}{*}{ Fonte de variação } & \multicolumn{3}{|c|}{ Altura do vilo } & \multicolumn{3}{|c|}{ Profundidade da cripta } & \multicolumn{3}{|c|}{ Relação vilo:cripta } \\
\hline & $\mathrm{D}$ & $\mathrm{J}$ & $\mathrm{I}$ & $\mathrm{D}$ & $\mathrm{J}$ & I & $\mathrm{D}$ & $\mathrm{J}$ & I \\
\hline DPD & 0,001 & 0,008 & 0,002 & 0,001 & 0,001 & 0,035 & 0,002 & 0,001 & 0,123 \\
\hline Dieta & 0,694 & 0,731 & 0,862 & 0,696 & 0,604 & 0,945 & 0,982 & 0,993 & 0,455 \\
\hline DPD $x$ dieta & 0,525 & 0,876 & 0,994 & 0,726 & 0,865 & 0,993 & 0,740 & 0,962 & 0,913 \\
\hline $\mathrm{CV} \%$ & 10,40 & 12,80 & 12,10 & 9,72 & 9,15 & 13,78 & 6,24 & 8,47 & 12,19 \\
\hline
\end{tabular}

CV: coeficiente de variação.

Foi observada, no entanto, variação $(\mathrm{P}<0,05)$ na altura dos vilos em função da idade (Tab.3 e 4), sendo que, no duodeno e no jejuno, os animais apresentaram queda na altura dos vilos aos sete dias pós-desmame, seguida de recuperação aos 14 dias, confirmando o que tem sido observado por diversos autores (Xu et al., 2000; Pluske,
2001). Marion et al. (2005) não observaram diferenças na altura das vilosidades do jejuno de leitões desmamados aos sete dias e abatidos aos 10, 14 e 21 dias de idade. No íleo ocorreu queda na altura dos vilos na primeira semana pósdesmame, a qual persistiu até a segunda.

Tabela 3. Altura dos vilos $(\mu \mathrm{m})$, profundidade das criptas $(\mu \mathrm{m})$ e relação vilo:cripta do duodeno (D), jejuno (J) e íleo (I) de leitões, em função do número de dias pós-desmame e da dieta

\begin{tabular}{|c|c|c|c|c|c|c|c|c|c|}
\hline & \multicolumn{3}{|c|}{ Altura do vilo } & \multicolumn{3}{|c|}{ Profundidade da cripta } & \multicolumn{3}{|c|}{ Relacão vilo:cripta } \\
\hline & $\mathrm{D}$ & $\mathbf{J}$ & $\mathrm{I}$ & $\mathrm{D}$ & $\mathrm{J}$ & $\mathrm{I}$ & $\mathrm{D}$ & $\mathrm{J}$ & I \\
\hline \multicolumn{10}{|l|}{ Dias pós-desmame } \\
\hline 0 & 388 & 299 & 220 & 134 & 89 & 59 & 2,88 & 3,37 & 3,75 \\
\hline 7 & 325 & 262 & 198 & 109 & 81 & 58 & 3,00 & 3,22 & 3,44 \\
\hline 14 & 335 & 281 & 191 & 108 & 74 & 53 & 3,11 & 3,80 & 3,62 \\
\hline \multicolumn{10}{|l|}{ Dietas } \\
\hline Dieta basal (DB) & 354 & 282 & 203 & 118 & 82 & 56 & 3,00 & 3,46 & 3,65 \\
\hline $\mathrm{DB}+$ glutamina & 344 & 288 & 208 & 115 & 83 & 57 & 3,00 & 3,47 & 3,72 \\
\hline $\mathrm{DB}+$ prebiótico & 343 & 278 & 203 & 115 & 81 & 57 & 2,98 & 3,44 & 3,59 \\
\hline DB + óleo Peixe & 355 & 274 & 199 & 119 & 75 & 58 & 2,99 & 3,47 & 3,46 \\
\hline
\end{tabular}

Tabela 4. Equações de regressão da altura dos vilos, profundidade das criptas e relação vilo:cripta do duodeno, jejuno e íleo de leitões, em função do número de dias pós-desmame

\begin{tabular}{lll}
\hline & $\begin{array}{l}\text { Equação } \\
\text { Variável }(\mathrm{Y})\end{array}$ & $\mathrm{R}^{2}$ \\
\hline Altura dos vilos $(\mu \mathrm{m})$ & & \\
\hline Duodeno & $\mathrm{Y}=388-14,57 \mathrm{X}+0,77 \mathrm{X}^{2}$ & 0,31 \\
Jejuno & $\mathrm{Y}=299-10,15 \mathrm{X}+0,63 \mathrm{X}^{2}$ & 0,20 \\
Íleo & $\mathrm{Y}=217-2,01 \mathrm{X}$ & 0,21 \\
\hline Profundidade das criptas $(\mu \mathrm{m})$ & & 0,47 \\
\hline Duodeno & $\mathrm{Y}=134-5,60 \mathrm{X}+0,27 \mathrm{X}^{2}$ & 0,41 \\
Jejuno & $\mathrm{Y}=88-1,01 \mathrm{X}$ & 0,11 \\
Íleo & $\mathrm{Y}=59,96-0,45 \mathrm{X}$ & 0,22 \\
\hline Relação vilo:cripta & & 0,43 \\
\hline Duodeno & $\mathrm{Y}=2,88+0,02 \mathrm{X}$ & \\
Jejuno & $\mathrm{Y}=3,37-0,07 \mathrm{X}+0,01 \mathrm{X}^{2}$ & \\
\hline
\end{tabular}


A profundidade das criptas não foi alterada $(\mathrm{P}>0,05)$ pela adição dos agentes tróficos na dieta basal, porém estas foram alteradas em função da idade pós-desmame $(\mathrm{P}<0,05)$, apresentando valores mais baixos aos sete e 14 dias pós-desmame (Tab. 3 e 4), quando comparados ao dia do desmame. Diferentemente, Tucci (1999) observou aumento na profundidade das criptas aos sete dias pós-desmame. Maior valor de profundidade das criptas indica maior atividade proliferativa celular, para garantir adequada taxa de renovação epitelial e compensar as perdas na altura dos vilos (Pluske, 2001).

Os resultados obtidos neste experimento indicaram que a diminuição ocorrida na altura dos vilos provavelmente foi devido à diminuição da divisão celular nas criptas e não em função do aumento da taxa de extrusão. Por outro lado, a redução na altura dos vilos não foi tão drástica a ponto de estimular um aumento na atividade proliferativa nas criptas, uma vez que estas diminuíram de tamanho e a relação vilo:cripta aumentou com a idade. Santos et al. (2002b) observaram maior valor da relação vilo:cripta com a adição de prebiótico à dieta de leitões. Valores altos de relação vilo:cripta indicam presença de maior quantidade de enterócitos maduros e funcionais.

Os animais deste experimento foram mantidos em ambiente controlado e temperatura termoneutra, além de receberem na dieta préinicial uma quantidade alta de leite em pó, o que pode reduzir, em parte, o estresse da desmama, com menores alterações na morfologia intestinal.

Na Tab. 5, mostram-se as probabilidades (teste F) obtidas pela análise de variância da densidade dos vilos no intestino delgado dos leitões, em função do número de dias pós-desmame e das dietas.

Tabela 5. Probabilidades (teste F) obtidas pela análise de variância para a densidade de vilos do intestino delgado dos leitões, em função do número de dias pós-desmame (DPD) e da dieta

\begin{tabular}{cccc}
\hline Fonte de variação & Duodeno & Jejuno & Íleo \\
\hline DPD & 0,001 & 0,002 & 0,066 \\
Dieta & 0,910 & 0,835 & 0,974 \\
DPD x dieta & 0,934 & 0,496 & 0,230 \\
\hline CV \% & 28,34 & 21,42 & 16,57 \\
\hline
\end{tabular}

CV: coeficiente de variação.

Foi observada redução $(\mathrm{P}<0,05)$ na densidade de vilos no duodeno e no jejuno em função do número de dias pós-desmame (Tab. 5, 6 e 7), o que se deveu ao aumento no diâmetro destes. Essa diminuição da densidade dos vilos, em função do aumento da idade dos animais, também foi observada em frangos de corte, por Maiorka et al. (2000), e em leitões desmamados, por Budiño et al. (2005).
Não foi constatado efeito da interação dieta versus idade $(\mathrm{P}<0,05)$; a inclusão dos aditivos estudados não alterou a densidade dos vilos, porém, quando se observaram os dados em cada semana, ficou evidente o aumento de $35 \%$ no número de vilos no duodeno e de $23 \%$ no jejuno, em relação à dieta não suplementada, e aumento de $44 \%$ e $42 \%$ no número de vilos no duodeno e jejuno, respectivamente, para os animais suplementados com glutamina.

Tabela 6. Médias da densidade de vilos (número de vilos $/ 539.220 \mu \mathrm{m}^{2}$ ) do intestino delgado dos leitões, em função do número de dias pós-desmame e da dieta

\begin{tabular}{cccc}
\hline Dias pós-desmame & Duodeno & Jejuno & Íleo \\
\hline 0 & 58 & 53 & 52 \\
7 & 43 & 51 & 52 \\
14 & 34 & 37 & 44 \\
\hline Dieta & & & 48 \\
Dieta basal (DB) & 42 & 45 & 50 \\
DB + glutamina & 47 & 49 & 49 \\
DB + prebiótico & 45 & 48 & 49 \\
DB + óleo peixe & 45 & 46 & \\
\hline
\end{tabular}


Efeito da adição de agentes...

Tabela 7. Equações de regressão da densidade (número de vilos $/ 539.220 \mu \mathrm{m}^{2}$ ) de vilos do intestino delgado dos leitões, em função do número de dias pós-desmame

\begin{tabular}{lll}
\hline \multirow{2}{*}{ Segmento do intestino } & Equação & \multirow{2}{*}{$\mathrm{R}^{2}$} \\
\hline Duodeno & $\mathrm{Y}=$ densidade $\mathrm{X}=$ dias pós-desmame & 0,40 \\
Jejuno & $\mathrm{Y}=57,06-1,73 \mathrm{X}$ & 0,25 \\
\hline
\end{tabular}

Outro fato importante é que este aumento, embora não significativo, da densidade dos vilos dos animais que receberam suplementação de $1 \%$ de glutamina na dieta, em relação ao tratamento controle, não foi acompanhado de redução na sua altura, indicando maior área para digestão e absorção de nutrientes da dieta. Em frangos de corte, Silva (2001) observou aumento na densidade dos vilos com a adição de glutamina à dieta, porém Maiorka et al. (2000) obtiveram valores semelhantes de densidade com a inclusão ou não de glutamina. $\mathrm{O}$ mecanismo pelo qual a glutamina favorece a condição da mucosa intestinal pode ser por meio do aumento da síntese da enzima ornitina descarboxilase (Kandil et al., 1995), a qual aumenta a produção de poliaminas que atuam na maturação e regeneração da mucosa intestinal (Wang et al., 1998), ou pela diminuição da morte celular (Chow e Zhang, 1998).

Para suínos, a predominância da glutamina no leite da porca sugere que esse aminoácido exerce importante papel no desenvolvimento e no crescimento de leitões (Abreu e Donzele, 2008), e que as dietas normalmente utilizadas no desmame possivelmente não suprem a necessidade desse aminoácido para garantir a alta atividade metabólica dos enterócitos, bem como sua proliferação nas primeiras semanas pósdesmame (Wu et al., 2006).

Na Tab. 8, são apresentadas as probabilidades (teste F) obtidas pela análise de variância dos dados de altura, largura e densidade dos microvilos e área de superfície apical dos enterócitos dos diferentes segmentos do intestino delgado.

Observou-se que os aditivos utilizados não afetaram $(\mathrm{P}>0,05)$ os parâmetros analisados, com exceção da largura dos microvilos no duodeno (Tab. 9), que diminuiu com a substituição do óleo de soja pelo óleo de peixe na dieta basal. Foi observada redução $(\mathrm{P}<0,05)$ na altura dos microvilos do duodeno aos sete dias pósdesmame, com aumento aos 14 dias, e aumento na largura dos microvilos no jejuno em função do número de dias pós-desmame (Tab. 9 e 10).

Tabela 8. Probabilidades (teste F) obtidas pela análise de variância para a altura, largura e densidade de microvilos e área de superfície apical dos enterócitos do intestino delgado dos leitões, em função do número de dias pós-desmame (DPD) e da dieta

\begin{tabular}{|c|c|c|c|c|c|c|c|c|}
\hline \multirow{2}{*}{ Fonte de variação } & \multicolumn{4}{|c|}{ Duodeno } & \multicolumn{4}{|c|}{ Jejuno } \\
\hline & Altura & Largura & Densidade & Área & Altura & Largura & Densidade & Área \\
\hline DPD & 0,027 & 0,533 & 0,162 & 0,705 & 0,264 & 0,012 & 0,117 & 0,809 \\
\hline Dieta & 0,902 & 0,013 & 0,332 & 0,554 & 0,437 & 0,343 & 0,558 & 0,919 \\
\hline DPD $x$ dieta & 0,614 & 0,065 & 0,664 & 0,420 & 0,229 & 0,269 & 0,774 & 0,865 \\
\hline $\mathrm{CV} \%$ & 20,32 & 5,46 & 15,44 & 36,82 & 20,31 & 7,68 & 20,20 & 38,85 \\
\hline
\end{tabular}

$\mathrm{CV}$ : coeficiente de variação.

A densidade dos microvilos e a área da superfície apical dos enterócitos não foram alteradas pelos aditivos testados nem pela idade dos animais. Cera et al. (1988) observaram redução na altura dos microvilos do jejuno de leitões, entre três e sete dias após o desmame. Budiño et al. (2005) também não observaram diferenças na altura dos microvilos no duodeno e jejuno em leitões suplementados com prebiótico (FOS). 
Tabela 9. Médias da altura $(\mu \mathrm{m})$, largura $(\mu \mathrm{m})$ e densidade $\left(\mathrm{n}^{\mathrm{o}}\right.$ de microvilos $\left./ \mu \mathrm{m}^{2}\right)$ de microvilos e área de superfície apical dos enterócitos $\left(\mu \mathrm{m}^{2}\right)$, em função do número de dias pós-desmame e da dieta

\begin{tabular}{|c|c|c|c|c|c|c|c|c|}
\hline & \multicolumn{4}{|c|}{ Duodeno } & \multicolumn{4}{|c|}{ Jejuno } \\
\hline & Altura & Largura & Densid. & Área & Altura & Largura & Densid. & Área \\
\hline \multicolumn{9}{|l|}{ Dias pós-desmame } \\
\hline 0 & 0,94 & 0,08 & 110 & 467 & 1,01 & 0,08 & 119 & 527 \\
\hline 7 & 0,74 & 0,08 & 98 & 412 & 0,91 & 0,08 & 99 & 471 \\
\hline 14 & 0,79 & 0,08 & 101 & 432 & 0,88 & 0,09 & 105 & 507 \\
\hline \multicolumn{9}{|l|}{ Dieta } \\
\hline Dieta basal (DB) & 0,83 & $0,085^{\mathrm{A}}$ & 95 & 497 & 0,88 & 0,08 & 102 & 464 \\
\hline $\mathrm{DB}+$ glutamina & 0,82 & $0,080^{\mathrm{AB}}$ & 103 & 388 & 0,93 & 0,08 & 106 & 504 \\
\hline $\mathrm{DB}+$ prebiótico & 0,86 & $0,081^{\mathrm{AB}}$ & 104 & 440 & 0,92 & 0,08 & 116 & 521 \\
\hline $\mathrm{DB}+$ óleo peixe & 0,80 & $0,078^{\mathrm{B}}$ & 109 & 423 & 1,02 & 0,08 & 108 & 523 \\
\hline
\end{tabular}

Valores seguidos por letras distintas na mesma coluna diferem pelo teste Tukey $(\mathrm{P}<0,05)$.

Tabela 10. Equações de regressão da altura $(\mu \mathrm{m})$ de microvilo no duodeno e largura $(\mu \mathrm{m})$ no jejuno em função do número de dias pós-desmame

\begin{tabular}{lll}
\hline Variável (Y) & $\begin{array}{l}\text { Equação } \\
\text { X }=\text { dias pós-desmame }\end{array}$ & $\mathrm{R}^{2}$ \\
\hline Altura do microvilo no duodeno & $\mathrm{Y}=0,936-0,045 \mathrm{X}+0,002 \mathrm{X}^{2}$ & 0,16 \\
Largura do microvilo no jejuno & $\mathrm{Y}=0,0077+0,0005 \mathrm{X}$ & 0,24 \\
\hline
\end{tabular}

Os aditivos estudados não alteraram $(\mathrm{P}>0,05) \mathrm{o}$ desempenho dos leitões após o desmame (Tab. 11). Apesar disso, a adição de $1 \%$ de glutamina à dieta basal resultou em aumento de $21 \%$ no ganho de peso diário e melhora de $23 \%$ na conversão alimentar, nas duas primeiras semanas pós-desmame. Esta melhora no desempenho de leitões que receberam glutamina na dieta também foi relatada por Wu et al. (1996), que observaram melhora de $25 \%$ na conversão alimentar, na segunda semana pós-desmame.

Tabela 11. Ganho de peso diário (GPD), consumo de ração diário (CRD) e conversão alimentar (CA) dos leitões de acordo com as dietas na primeira semana pós-desmame (1 a 7 dias), na segunda semana pósdesmame ( 8 a 14 dias) e período total ( 1 a 14 dias)

\begin{tabular}{lccccccccc}
\hline \multicolumn{1}{c}{ Dieta } & \multicolumn{3}{c}{ G P D $(\mathrm{g})$} & \multicolumn{3}{c}{ C R D $(\mathrm{g})$} & \multicolumn{3}{c}{ C A } \\
\cline { 2 - 11 } & 1 a 7 & 8 a 14 & 1 a 14 & 1 a 7 & 8 a 14 & 1 a 14 & 1 a 7 & 8 a 14 & 1 a 14 \\
\hline Dieta basal (DB) & 180 & 283 & 224 & 264 & 429 & 357 & 1,56 & 2,04 & 1,72 \\
DB + glutamina & 193 & 352 & 272 & 272 & 431 & 345 & 1,41 & 1,26 & 1,32 \\
DB + prebiótico & 170 & 269 & 205 & 247 & 375 & 305 & 1,87 & 1,50 & 1,72 \\
DB + óleo peixe & 172 & 285 & 226 & 248 & 394 & 329 & 1,70 & 1,65 & 1,58 \\
\hline Média geral & 179 & 297 & 232 & 258 & 407 & 334 & 1,64 & 1,61 & 1,59 \\
\hline CV\% & 42,47 & 28,76 & 23,48 & 23,22 & 15,24 & 14,65 & 50,08 & 47,23 & 16,34 \\
\hline P (teste F) & 0,913 & 0,453 & 0,298 & 0,786 & 0,428 & 0,406 & 0,607 & 0,459 & 0,101 \\
\hline
\end{tabular}

$\mathrm{CV}$ : coeficiente de variação.

\section{CONCLUSÕES}

As dietas testadas não foram eficientes em prevenir a redução na altura dos vilos do intestino delgado dos leitões ao desmame. A densidade dos vilos diminuiu com o número de dias pós-desmame, e a adição de glutamina na dieta basal aumentou a densidade dos vilos no jejuno, aos sete dias pós-desmame. A ultraestrutura do intestino delgado praticamente não foi alterada pelas dietas testadas nem pela idade pós-desmame.

\section{REFERÊNCIAS BIBLIOGRÁFICAS}

ABREU, M.L.T.; DONZELE, J.L. Glutamina na nutrição de leitões. In: SIMPÓSIO SOBRE MANEJO E NUTRIÇÃO DE AVES E SUÍNOS, 5., 2008. Cascavel, PR. Anais... Cascavel, PR: CBNA, 2008. p.170. 
BUDIÑO, F.E.L.; THOMAZ, M.C.; KRONKA, R.N. et al. Effect of probiotic and, or prebiotic inclusion in weaned piglet diets on structure and ultra-structure of small intestine. Braz. Arch. Biol. Technol., v. 48, p. 921-929, 2005.

CERA, K.R.; MAHAN, D.C.; CROSS, R.F. et al. Effect of age, weaning and postweaning diet on small intestinal growth and jejunal morphology in young swine. J. Anim. Sci., v.66, p.574-584, 1988.

CHOW, A.; ZHANG, R. Glutamine reduces heat shock-induced cell death in rat intestinal epithelial cells. J. Nutr., v.128, p.1296-1301, 1998.

FERRER, R.; PLANAS, J.M.; MORETÓ, M. Cell apical surface area in enterocytes from chicken small and large intestine during development. Poult. Sci., v.74, p.1995-2002, 1995.

IJI, P.A.; TIVEY, D.R. Natural and synthetic oligosaccharides in broiler chicken diets. World's Poult. Sci. J., v.54, p.129-143, 1998.

KANDIL, H.M.; ARGENZIO, R.A.; CHEN, W. et al. L-glutamine and L-asparagine stimulate ODC activity and proliferation in a porcine jejunal enterocyte line. Am. J. Physiol., v.269, p.G591-G599, 1995.

LESKANICH, C.O.; NOBLE, R.C. Review article: The comparative roles of polynsaturated fatty acids in pig neonatal development. Br. J. Nutr., v.81, p.87-106, 1999.

LÓPEZ-PEDROSA， J.M.; RAMÍREZ， M.; TORRES, M.I. et al. Dietary phospholipids rich in long-chain polynsaturated fatty acids improve the repair of small intestine in previously malnourished piglets. J. Nutr., v.129, p.11491155, 1999.

MACARI, M. Aspectos fisiológicos do sistema digestivo das aves. SEMANA ACADÊMICA VETERINÁRIA, 8., 1998. São Paulo. Anais... São Paulo: [s.n.] 1998. p.4-18.

MAIORKA, A.; SILVA, A.V.F.; SANTIN, E. et al. Influência da suplementação de glutamina sobre o desempenho e o desenvolvimento dos vilos e criptas do intestino delgado de frangos. Arq. Bras. Med. Vet. Zootec., v.52, p.487-490, 2000.
MARION, J.; PETERSEN, Y.M.; ROMÉ, V. et al. Early weaning stimulates intestinal brush border enzyme activities in piglets, mainly at the posttranscriptional level. J. Pediatr. Gastroenterol. Nutr., v.41, p.401-410, 2005.

NUTRIENT requirements of swine. 10.ed. Washington, DC: National Academy of Sciences, 1998.

PIMENTA, M.E.S.G.; VARASCHIN, M.S.; FIALHO, E.T. et al. Altura de vilosidades intestinais de leitões submetidos após o desmame a diferentes fontes e níveis de lipídeos na ração. In: REUNIÃO ANUAL DA SOCIEDADE BRASILEIRA DE ZOOTECNIA, 39., 2002, Recife, PE. Anais... Recife, PE: SBZ, 2002. CDROM.

PLUSKE, J.R. Morphological and functional changes in the small intestine of the newly weaned pig. In: PIVA, A.; KNUDSEN, K.E.B.; LINDBERG, J.E. Gut environment of pigs. Nottingham: University Press, 2001. p.1-27.

SANTOS, W.G.; FILGUEIRAS, E.P.; BERTECHINI, A.G. et al. Efeito da manose como prebiótico sobre a morfologia intestinal de leitões na fase de creche. In: REUNIÃO ANUAL DA SOCIEDADE BRASILEIRA DE ZOOTECNIA, 39., 2002a, Recife, PE. Anais... Recife, PE: SBZ, 2002. CD-ROM.

SANTOS, W. G.; FILGUEIRAS, E.P.; SILVA, H.O. et al. Efeito da manose como prebiótico sobre a morfologia intestinal (relação vilosidade/cripta) de leitões na fase de creche. In: REUNIÃO ANUAL DA SOCIEDADE BRASILEIRA DE ZOOTECNIA, 39., Recife, PE, 2002b. Anais... Recife, PE: SBZ, 2002. CDROM.

Statistical Analysis System. User's Guide. Release 6.12 Edition. Cary, N.C.: SAS Institute, $1993.956 \mathrm{p}$.

SILVA, A.V.F. Efeitos da restrição alimentar precoce e da glutamina no desempenho e na mucosa intestinal em frangos. 2001. 77f. Tese (Doutorado) - Faculdade de Ciências Agrárias e Veterinárias, Universidade Estadual Paulista, Jaboticabal, SP. 
SPRING, P. Yeast's secret weapon aids animal production, In: SIMPÓSIO SOBRE ADITIVOS ALTERNATIVOS NA NUTRIÇÃO ANIMAL, 2000. Campinas, Anais... Campinas: Colégio Brasileiro de Nutrição Animal, 2000. p.41-50.

STRYER, L. Bioquímica. 3.ed. Rio de Janeiro: Guanabara Koogan, 1992. 881p.

TUCCI, F.M. Estudo da adição de virginiamicina e $\beta$-glucanase exógena às rações de leitões e seus efeitos sobre o desempenho $e$ morfologia intestinal. 1999. 76f. Dissertação (Mestrado) - Faculdade de Medicina Veterinária e Zootecnia, Universidade de São Paulo, Pirassununga, SP.

WANG, J.Y.; LI, J.; PATEL, A.R. Synergistic induction of ornithine decarboxylase by asparagine and gut peptides in intestinal crypt cells. Am. J. Physiol., v.274, p.C1476-C1484, 1998.

WU, G.; BAZER, F.W.; WALLACE, J.M. et al. Intrauterine growth retardation: Implications for the animal sciences. J. Anim. Sci., v.84, p.23162337, 2006.
WU, G.; KNABE, D.A. Free and protein-bound amino acids in sow's colostrum and milk. $J$. Nutr., v.124, p.415-424, 1994.

WU, G.; MEIER, S.A.; KNABE, D.A. Dietary glutamine supplementation prevents jejunal atrophy in weaned pigs. J. Nutr., v.126, p.25782584, 1996.

XU, R.J.; WANG, F.; ZHANG, S.H. Postnatal adaptation of the gastrointestinal tract in neonatal pigs: a possible role of milk-borne growth factors. Liv. Prod. Sci., v.66, p.95-107, 2000.

YI, G.F.; CARROL, J.A.; ALLE, G.L. et al. Effect of glutamina and spray-dried on growth performance, small intestinal morphology, and immune responses of Escherichia coli I $\mathrm{K}^{+} 8^{+}$challenged weaned pigs. J. Anim. Sci., v.83, p.634-643, 2005. 